\title{
DEVELOPMENT AND VALIDATION OF UV-VISIBLE SPECTROPHOTOMETRIC METHOD FOR ESTIMATION OF TADALAFIL IN BULK AND FORMULATION
}

\author{
SHRISHAIL M. GHURGHURE ${ }^{1}$, MANISHA S DYAWARKONDA ${ }^{*}$, SACHIN YANJANE1 \\ 1D. S. T. S. Mandal's College of Pharmacy Solapur 413004. Maharashtra, India \\ Email: manishadyawarkonda@gmail.com
}

Received: 20 Jan 2020, Revised and Accepted: 19 Mar 2020

\section{ABSTRACT}

Objective: A new simple, sensitive, precise and reproducible spectroscopic method was developed for the determination of Tadalafil in Pharmaceutical formulation with Dimethyl Sulfoxide.

Methods: The UV spectrum of Tadalafil in Dimethyl sulfoxide (DMSO) showed $\lambda$ max at $285.6 \mathrm{~nm}$. Beer's law is valid in the concentration range of $10-60 \mu \mathrm{g} / \mathrm{ml}$. This method was validated for linearity, accuracy, precision, ruggedness and robustness.

Results: The method was demonstrated excellent linearity over the range of $10-60 \mu \mathrm{g} / \mathrm{ml}$ with regression equation $\mathrm{y}=0.0337 \mathrm{x}-0.1343$ and regression correlation $\mathrm{R}^{2}=0.998$. Moreover, the method was found to be highly sensitive with LOD $(2.44 \mu \mathrm{g} / \mathrm{ml})$ and LOQ (7.40 $\left.\mu \mathrm{g} / \mathrm{ml}\right)$.

Conclusion: Based on results, the proposed method can be successfully applied for assay of Tadalafil in various pharmaceutical dosage forms.

Keywords: Tadalafil, DMSO, UV-spectroscopic method.

(C) 2020 The Authors. Published by Innovare Academic Sciences Pvt Ltd. This is an open access article under the CC BY license (http://creativecommons.org/licenses/by/4.0/) DOI: http://dx.doi.org/10.22159/ijcpr.2020v12i3.38310. Journal homepage: https://innovareacademics.in/journals/index.php/ijcpr

\section{INTRODUCTION}

The common sexual problem in men is Erectile Dysfunction (ED). The meaning of ED is a difficulty in initiating or maintaining penile erection adequate for sexual activity. ED has a weight effect on intimate relationships, quality of life, and overall self-esteem for men [1-4].

Erectile dysfunction (ED) is treated with PDF5 inhibitors. Tadalafil is used to treat ED in men and it is an impotence agent. It is a selective inhibitor of cyclic guanosine monophosphate (cGMP)-specific phosphodiesterase type 5 (PDF5). Tadalafil has also been quantified in pharmaceutical prep rations, human serum and biological fluids by HPLC with UV detection. Although the UV spectrophotometric method is commonly used in industrial laboratories due to its simplicity, selectivity and sensitivity $[5,6]$.

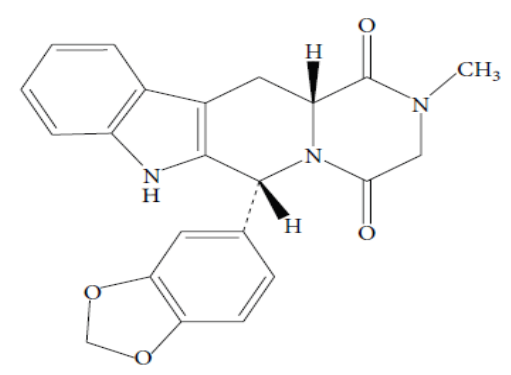

Fig. 1: Chemical structure of tadalafil

Tadalafil (TD) is (6R, 12aS)-6-(1,3-benzodioxal-5-yl)-2,3,6,7,12,12ahexahydro-2-methylpyrazino $\left[1^{\prime}, 2^{\prime}: 1,6\right]$ pyrido[3,4-b] indole-1,4dione [3]. It has molecular formula of $\mathrm{C}_{22} \mathrm{H}_{19} \mathrm{~N}_{3} \mathrm{O}_{4}$ and molecular weight of $389.4 \mathrm{gm} / \mathrm{ml}$. Tadalafil is a white powder and has a melting point $301{ }^{\circ} \mathrm{C}-302{ }^{\circ} \mathrm{C}$. The drug substance is practically insoluble in water and soluble in methanol [7-9].

The aim of the present work was to develop a simple, rapid, accurate and sensitive UV spectrophotometric method for the determination of tadalafil in bulk and pharmaceutical formulation.

\section{MATERIALS AND METHODS}

Tadalafil was purchased and Dimethyl Sulfoxide was used of analytical grade.

\section{Instruments}

A UV visible double beam spectrophotometer [systronics 2201] and Shimadzu 1800-UV spectrophotometer with $1 \mathrm{~cm}$ quartz cuvettes were used for all absorbance measurements. All weights were taken on an analytical balance (Shimadzu). Sonicator (Oscar Ultrasonic Cleaner Microclean) was used for dissolving Tadalafil in DMSO.

\section{Experimental}

Preparation of standard stock solution

The standard stock solution of Tadalafil was prepared by dissolving accurately weighed $10 \mathrm{mg}$ in $10 \mathrm{ml}$ of DMSO to obtain $1000 \mu \mathrm{g} / \mathrm{ml}$. It was further diluted to get a standard solution of $100 \mu \mathrm{g} / \mathrm{ml}$.

\section{Method development}

Aliquot from the standard solution was taken and diluted with DMSO to get concentration of $20 \mu \mathrm{g} / \mathrm{ml}$ and it was scanned between 200-400 nm, which showed the maximum absorbance at $285.6 \mathrm{~nm}$.

Procedure for determination of Assay of Tadalafil in Pharmaceutical formulation

Ten Tadalafil (Tadalista) tablets (label claim $20 \mathrm{mg}$ ) were weighed and transferred into mortar triturated into fine powder by using pestle. Tablet powder equivalent to $10 \mathrm{mg}$ of tadalafil was transferred into 10 $\mathrm{ml}$ volumetric flask and $10 \mathrm{ml}$ of DMSO was added to dissolve the powder. The solution sonicated for $10 \mathrm{~min}$. After sonication, filtration was carried out by using Whatman filter paper. From the appropriate filtrate conc. of aliquots were taken and diluted to $10 \mathrm{ml}$ with DMSO to get the final conc. of $10-60 \mu \mathrm{g} / \mathrm{ml}[10,11]$.

\section{Procedure for plotting a calibration curve}

Aliquots of working standard solution were further diluted with DMSO to get the concentration of $10,20,30,40$, and $50 \mu \mathrm{g} / \mathrm{ml}$. Finally, the prepared standards were measured at $285.6 \mathrm{~nm}$ in each case against a solvent Dimethyl Sulfoxide as blank. 


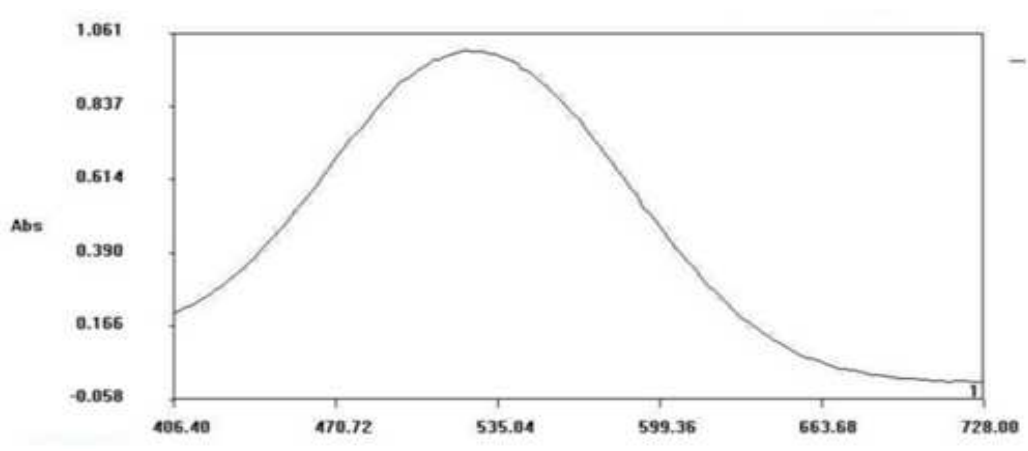

Fig. 2: UV-spectra of tadalafil

\section{Linearity}

The linearity was confirmed by taking aliquots of concentration of $10-60 \mu \mathrm{g} / \mathrm{ml}$ and absorbance was measured. It was performed in a single day only. The obtained absorbance shows a good regression coefficient at wavelength $285.6 \mathrm{~nm}$. The slope and intercept values were recorded. The linearity was plotted against the absorbance of Tadalafil vs concentration of Tadalafil.

\section{Accuracy}

The accuracy is parameter of an analytical method, which describes the closeness to the rest results obtained by that method to the theoretical value. The standard addition method is used to analyze accuracy, which is performed by using previously analyzed standard solutions. The percentage relative standard deviation and percentage recovery were analyzed by using standard solutions [12].

\section{Range}

The range is the analytical parameter of an interval between lower and upper concentration limit of an analyte i.e. 10-60 $\mathrm{gg} / \mathrm{ml}$ [12].

\section{Precision}

The precision is performed as inter-day and intra-day. Intra-day precision was performed in one day and inter-day precision was performed in three days. Tadalafil was evaluated at a concentration $30 \mu \mathrm{g} / \mathrm{ml}$. The percentage RSD for intra-day precision was found to be $0.85 \%$ and inter-day precision was found to be $0.95 \%$ [13].

\section{Limit of detection (LOD)}

The limit of detection (LOD) or lower limit of detection is the lowest quantity of substances that can be able to distinguish from the absence of the substance with a stated experimental level [14]. The LOD was found to be $2.44 \mu \mathrm{g} / \mathrm{ml}$. Hence the parameter was found to be validated (table 1 ).

$$
\mathrm{LOD}=3.3 \mathrm{Sa} / \mathrm{b}
$$

\section{Limit of quantification (LOQ)}

The limit of quantification (LOQ) is the lowest concentration of the substance that can be accurately measured under specified experimental conditions. LOQ is used to determine impurities or degradation products. The LOQ was found to be $7.40 \mu \mathrm{g} / \mathrm{ml}$. Hence the parameter was found to be validated (table 1) [15].

$$
\mathrm{LOQ}=10 \mathrm{Sa} / \mathrm{b}
$$

Table 1: Optimization parameters for method development of tadalafil

\begin{tabular}{ll}
\hline Parameters & Method values \\
\hline$\lambda$ max & $285.6 \mathrm{~nm}$ \\
Beer's law & $10-60 \mu \mathrm{g} / \mathrm{ml}$ \\
Regression equation $(\mathrm{Y}=\mathrm{mx}+\mathrm{c})$ & $\mathrm{y}=0.0337 \mathrm{x}-0.1343$ \\
Correlation coefficient $(\mathrm{r})$ & 0.998 \\
Intercept & 0.1343 \\
Slope & 0.0337 \\
$\mathrm{LOD}(\mu \mathrm{g} / \mathrm{ml})$ & 2.44 \\
$\mathrm{LOQ}(\mu \mathrm{g} / \mathrm{ml})$ & 7.40 \\
\hline
\end{tabular}

\section{Ruggedness}

The ruggedness is the study of the degree of reproducibility of test results obtained by a variety of external conditions like different analysts, laboratories, days and reagents. This study shown that there is no any influence of these conditions on test results [16].

\section{Robustness}

The robustness is the small but deliberate variations in method parameters such as temperature and stability of analytical solution [16].

\section{RESULTS AND DISCUSSION}

\section{Linearity}

Six different concentration of Tadalafil were prepared and analyzed. Then wavelength was found to be $285.6 \mathrm{~nm}$. The regression coefficient was found to be 0.998 . The absorbance was found in limit i.e. $0-2$. Hence, the analyzed was found to be validated (table 2) [17].

\section{Precision}

\section{Intra-day precision}

Intra-day precision was found within limit i.e. $30 \mu \mathrm{g} / \mathrm{ml}$ at $285.6 \mathrm{~nm}$; the relative standard deviation is less than $2 \%$. Hence the parameter was found to be validated (table 4) [18].

\section{Inter-day precision}

Inter-day precision was performed in two days and the obtained results of concentration $30 \mu \mathrm{g} / \mathrm{ml}$ at $285.6 \mathrm{~nm}$ shown that the relative standard deviation is less than $2 \%$. Hence the parameter was found to be validated (table 5) [18].

\section{Robustness}

The change in concentration i.e. $15 \mu \mathrm{g} / \mathrm{ml}$. The robustness was found to be within limit i.e. relative standard deviation is less than $2 \%$. Hence the parameter was found to be validated (table 6) [19]. 
Table 2: linearity of tadalafil

\begin{tabular}{lll}
\hline S. No. & Concentration $\mu \mathbf{g} / \mathbf{m l}$ & Absorbance \\
\hline 1. & 10 & 0.215 \\
2. & 20 & 0.508 \\
3. & 30 & 0.874 \\
4. & 40 & 1.253 \\
5. & 50 & 1.545 \\
6. & 60 & 1.876 \\
\hline
\end{tabular}

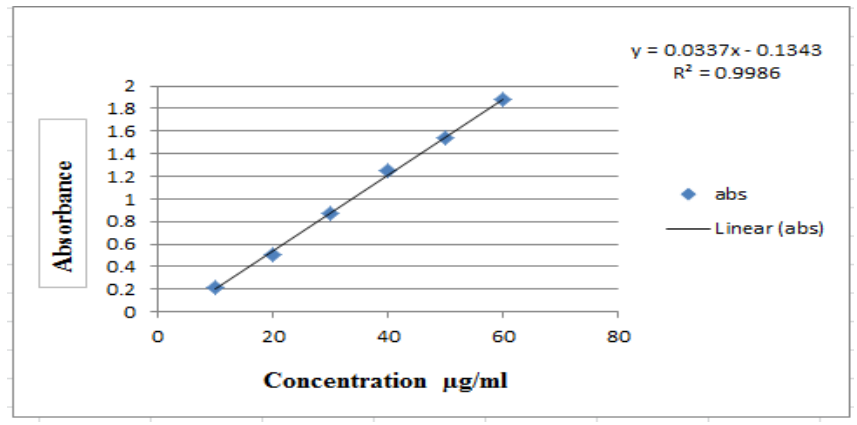

Fig. 3: Calibration curve of tadalafil

Table 3: Linearity of tadalafil tablet

\begin{tabular}{lll}
\hline S. No. & Concentration $(\boldsymbol{\mu g} / \mathbf{m l})$ & Absorbance \\
\hline 1 & 10 & 0.195 \\
2 & 20 & 0.369 \\
3 & 30 & 0.982 \\
4 & 40 & 0.898 \\
5 & 50 & 1.112 \\
6 & 60 & 1.355 \\
\hline
\end{tabular}

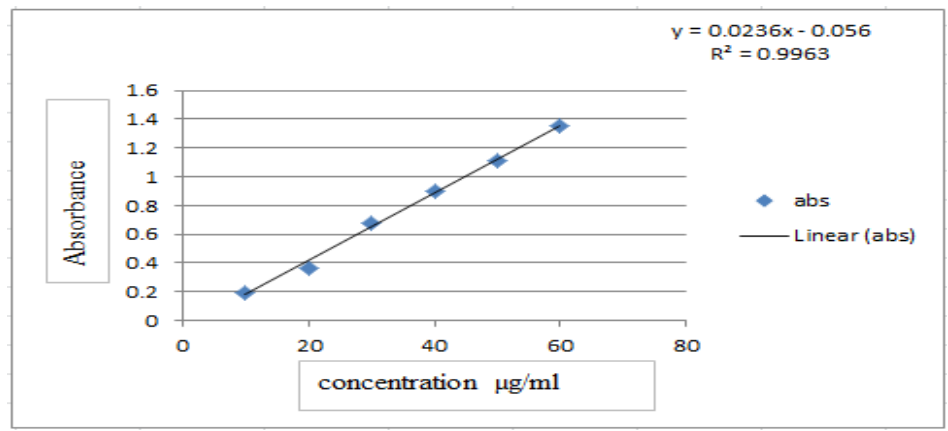

Fig. 4: linearity curve of tadalafil tablet

Table 4: Intraday precision

\begin{tabular}{lll}
\hline S. No. & Concentration $(\boldsymbol{\mu g} / \mathbf{m l})$ & Absorbance \\
\hline 1 & 30 & 0.874 \\
2 & 30 & 0.875 \\
3 & 30 & 0.873 \\
4 & 30 & 0.874 \\
5 & 30 & 0.877 \\
6 & 30 & 0.875 \\
SD & & 0.001366 \\
\%RSD & & $0.156204 \%$ \\
\hline
\end{tabular}

Table 5: Inter-day precision

\begin{tabular}{llll}
\hline S. No. & Concentration $(\boldsymbol{\mu g} / \mathbf{m l})$ & Absorbance Day 1 & Absorbance Day 2 \\
\hline 1 & 30 & 0.874 & 0.875 \\
2 & 30 & 0.875 & 0.874 \\
3 & 30 & 0.873 & 0.877 \\
4 & 30 & 0.874 & 0.874 \\
5 & 30 & 0.877 & 0.875 \\
6 & 30 & 0.875 & 0.874 \\
SD & & 0.001366 & 0.00116 \\
$\%$ RSD & & $0.156204 \%$ & $0.1336 \%$ \\
\hline
\end{tabular}


Table 6: Robustness

\begin{tabular}{lll}
\hline Wavelength & $285.6 \mathrm{~nm}$ & $285.6 \mathrm{~nm}$ \\
Concentration $(\mu \mathrm{g} / \mathrm{ml})$ & $15(\mu \mathrm{g} / \mathrm{ml})$ & $15(\mu \mathrm{g} / \mathrm{ml})$ \\
Absorbance & 0.352 & 0.351 \\
& 0.351 & 0.352 \\
& 0.353 & 0.354 \\
9 & 0.354 & 0.356 \\
SD & & 0.354 \\
& 0.351 & 0.001751 \\
\end{tabular}

Table 7: Ruggedness

\begin{tabular}{|c|c|c|c|}
\hline S. No. & Concentration $(\mu \mathrm{g} / \mathrm{ml})$ & $\begin{array}{l}\text { Absorbance } \\
\text { analyst1 }\end{array}$ & $\begin{array}{l}\text { Absorbance } \\
\text { analyst2 }\end{array}$ \\
\hline 1 & 30 & 0.508 & 0.506 \\
\hline 2 & 30 & 0.509 & 0.509 \\
\hline 3 & 30 & 0.510 & 0.507 \\
\hline 4 & 30 & 0.507 & 0.508 \\
\hline 5 & 30 & 0.508 & 0.506 \\
\hline 6 & 30 & 0.509 & 0.510 \\
\hline SD & & 0.001049 & o. 001633 \\
\hline$\%$ RSD & & $0.206255 \%$ & $0.321666 \%$ \\
\hline
\end{tabular}

\section{Ruggedness}

The change in analyst at concentration $30 \mu \mathrm{g} / \mathrm{ml}$ the obtained results shown that does not affected by it (table 7) [19].

\section{CONCLUSION}

The method was validated for the quantitative determination of Tadalafil tablets. The present method was simple, accurate, precise, rugged and reproducible and gives an acceptable recovery of the analyte, which can be directly easily applied to the analysis of the pharmaceutical formulation of Tadalafil [20-22].

\section{ACKNOWLEDGMENT}

Authors are thankful to the Principal, D. S. T. S. Mandal's College of Pharmacy, Solapur, for providing necessary facilities.

\section{FUNDING}

Nil

\section{AUTHORS CONTRIBUTIONS}

All the authors have contributed equally.

\section{CONFLICT OF INTERESTS}

Declare none

\section{REFERENCES}

1. Natarajan R, Prabhu C, Rajendran NN. Formulation and evaluation of oral jelly containing tadalafil. Int J Res Pharm Chem 2014;4:479-83.

2. Mohammad Yunoos, D Gowri Shankar, B Pragathi Kumar. The determination of tadalafil in the bulk and pharmaceutical dosage form. E-J Chem 2010;7:833-6.

3. Zamirkhan, Amod SP, Atul AS. Estimation of tadalafil in bulk material and in pharmaceutical formulation by using derivative spectroscopy. Int J Spectrosc 2014. p. 1-6. https://doi.org/10.1155/2014/392421

4. https.//en.m.wikipedia.org. [Last accessed on 10 Dec 2019]

5. http.//www.accessdata.fda.gov. [Last accessed on 10 Dec 2019]

6. SC Sweetman. The complete drug reference, Pharmaceutical Press: London, UK; 2007.

7. PB Reddy, KA Reddy, MS Reddy. RP-HPLC method for validation and stability-indicating for the determination of tadalafil API in pharmaceutical formulations. Res Pharm Biotechnol 2010;2:1-6.
8. MR Shashikanth, D Yada. Validation of stability indicating methods and method development for assay of tadalafil by HPLC. Int J ChemTech Res 2010;2:329-33.

9. VP Rane, Patil KR, Shinde DB, N Sangshetti. Estimation of tadalafil in bulk drug and pharmaceutical dosage form by stability indicating LC method. Chem Anal 2009;54:679-89.

10. SA Patel, NJ Patel. HPTLC method for determination of tadalafil in pharmaceutical dosage form. Am J PharmaTech Res 2011;1:138-46.

11. D Vijaya Durga, K Himabindu, Kavitha A, D Anil Kumar. Forced degradation studies, quantification and in vitro dissolution studies of tadalafil by spectrofluorimetry. Asian J Pharm Clin Res 2013;6:326-9.

12. Validation of analytical procedures: text and methodology. ICHGuidelines Q2 (RI); 2005.

13. Sisodiya Mayuri, S Ravindranath. Solubility enhancement, formulation development and evaluation of immediate-release tablet of antihypertensive drug tadalafil. J Drug Delivery Thera 2018;8:294-302.

14. Prakash M. Role of tadalafil in erectile dysfunction. INJRC 2009;20:250-2.

15. Mohammad Yasir Peerzade, Shakeel Memon, Kiran Bhise, Ansari Irfan Aamer. Development and validation of a uv-visible spectrophotometric method for estimation of ritonavir in bulk and formulation. Pharma Innovation J 2019;8:30-4.

16. Subhasis Dan, Magduma CS. Bioanalytical method development and validation of tadalafil with special emphasis on pharmacokinetic study in healthy Indian subjects for ODS formulation. Curr Anal Chem 2015;11:285-98.

17. PH Sonawane, Amit Khandekar, Chirag SR, Jawed Akhtar. Rapid estimation of tadalafil by reverse-phase high-performance liquid chromatography method in bulk and tablet formulation. Indian J Pharm Sci 2013;75:230-3.

18. Aboul Enein H, Ali I. Validated method for tadalafil analysis in pharmaceutical preparations by capillary electrophoresis. Chromatographia 2014;60:187-91.

19. Ahemad NA. Validated liquid chromatography-ultraviolet method for the quantitation of tadalafil in human plasma using liquid-liquid extraction. J Chromatography B 2007;852:403-8.

20. Anuj Modi Anurekha J, Vivek J, Shrivastava A. A validated UV spectrophotometric method for the determination of tadalafil in bulk and solid dosage form. JADR 2012;2:13-8.

21. Bhaskar Raju N, Mahaboob S, G Edukondalu. A novel RP-HPLC method for the quantification of tadalafil in formulations. Res Desk 2012;1:66-73. 